\title{
A New Kind of Crude Magnesium Extraction Process and Device
}

\author{
Jian-xun Ren ${ }^{1, *}$, Xiao-gang Wang ${ }^{2}$ and Li-bin Niu ${ }^{3}$
}

College of Material Science and Engineering, Xi'an University of Science and Technology, Xi'an 710055, P.R.China

\author{
Keywords: Mg reduction, Vertical Furnace, Inner Heating, Pidgeon Process
}

\begin{abstract}
In order to short reduction period, decrease energy consumption and lower labour-intensive in the production of $\mathrm{Mg}$ reduction, a kind of vertical and fast reduction $\mathrm{Mg}$ furnace was developed to come into continuous operation and automobile control, the novel furnace is heated by the inner-multiple-electrode, and comprised of two condenses, a vertical furnace, a vacuum system and several containers. The operation principle and process are briefly described, and there is several stronger merits over the steel retorts used in horizontal Pidgeon process.
\end{abstract}

\section{Introduction}

The current growth in the demand for magnesium is primarily driven by automotive industry for light weighting automobiles to reduce emissions. China is the largest producer of magnesium in the world, and supplies currently $40-50 \%$ of the world demand for magnesium. Magnesium production in China is based on a thermal process, known as the Pidgeon process. However, the horizontal Pidgeon reduction process currently deployed in China possesses a characteristic, i.e. inefficiency of heat and mass transfer occurred in the reduction process [1,2]. This inefficiency always leads to low productivity, high energy consumption, labour-intensive operation, large floor space and high capital investment [3]. The current domination of world production by the Pidgeon process mainly reflects the economic conditions of China rather than any inherent advantages of the Pidgeon process over electrolytic routes. Hence, this horizontal process confines its production scale.

\section{Operating Process of Vertical Reduction}

To overcome the shortcomings of the horizontal magnesium reduction process, a novel vertical and fast magnesium reduction process for large-scale production must be developed, in which the rate of heat and mass transfer during the reduction process can be enhanced [4].

After investigations from laboratory experiments to semi-industrialization scale, the investigation group puts forward a kind of new vertical reduction by inner-multiple-electrical heating, which can shorten reduction time, reduce energy consumption, low the labour-intensive, and come into automatic control.

The reactant material reduced in the new process is similar to those of the traditional Pidgeon process. Namely, the principal raw materials is dolomite ore, which is calcined at $1300^{\circ} \mathrm{C}$ in rotary or vertical batch furnaces. The calcining process yields 'dolime' which is then ground and mixed in a specific ratio with finely ground ferrosilicon containing $75 \%$ of silicon. Calcium fluoride may be added to the mixture as a catalyst. The mixture is pelletized to make briquettes for reduction in the reduction furnace.

The new vertical reduction system is mainly comprised of two condenses, a vertical furnace, a vacuum system and several containers. The sketch map and real device of the vertical reduction system used in the experiments is shown in Figure.1. 


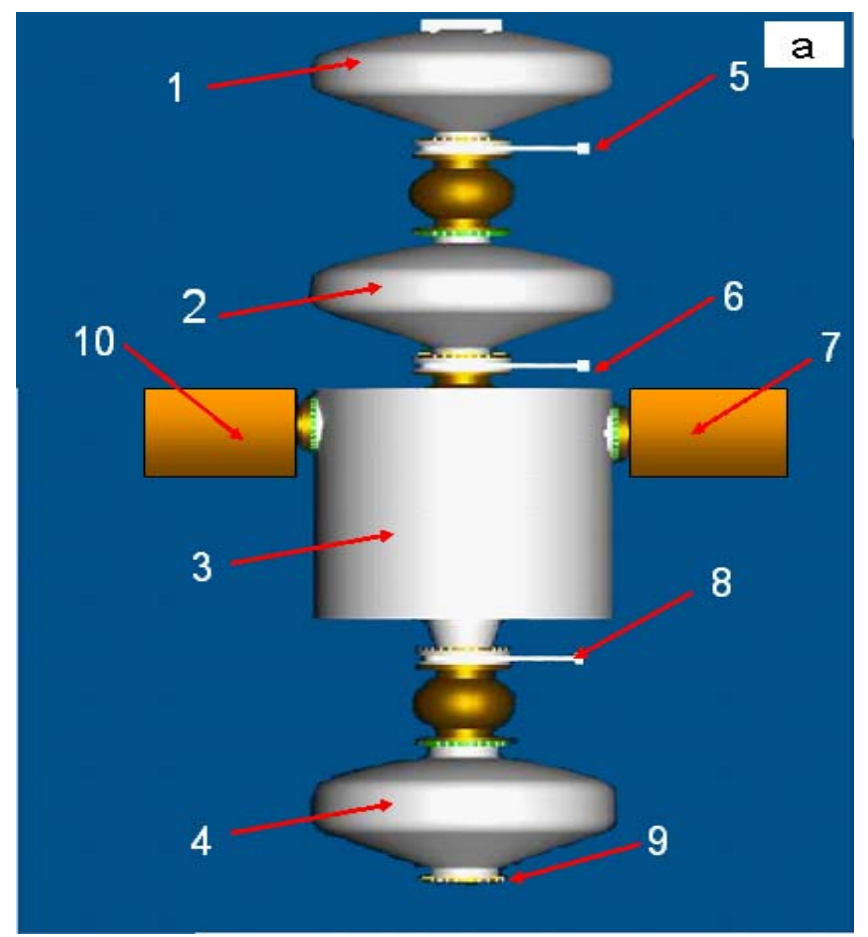

Figure 1. Sketch map of the vertical reduction system used in the experiments.

The two condenses as a shape cone, are made up high alloy stainless steel (marked 7 and 10 in Fig.1), they are located on both sides of the vertical furnace, and can alternately perform during operation. The sizes of the two condenses are $700 \mathrm{~mm}$ in diameter, and $800 \mathrm{~mm}$ in length.

The heating components inside vertical furnace are made up a series of graphite electrodes as a shape of plates called as multiple-electrical heating. Figure.2(a-b) are the temperature simulation results of the space between graphite electrodes under unloading and loading reactant material, respectively. The reactant material is charged into the gaps between graphite electrodes. It can be seen that when the time of heating is $2 \mathrm{~h}$, under the condition of the no charged reactant material, the temperature of the spaces between graphite electrodes is about $600{ }^{\circ} \mathrm{C}$, whereas under the condition of the charged reactant material, the temperature of the spaces between graphite electrodes is over $1200^{\circ} \mathrm{C}$. Clearly, the rate of heat transfer through inner-heating is $2-3 \mathrm{~h}$ and very faster than that outer-heating used in horizontal Pidgeon process (its reduction period is $8-10 \mathrm{~h}$ ).

Since the furnace is set vertically, instead of horizontally, not only the less space is occupied, but also the entire procedures of loading reactants material, as well as unloading the residue can process automatically and completely different from those for the horizontal reduction process.

The process can be carried out as following:

Prior to the operational process, the conditions of the vertical reduction system: every containers are empty, all of the valves are closed and the reduction furnace is preheated up to $600^{\circ} \mathrm{C}$ at the vacuum of $10-15 \mathrm{~Pa}$.

Firstly, the reactant material is charged into the container 1 which is under normal temperature $\left(25^{\circ} \mathrm{C}\right)$ and pressure $(1 \mathrm{~atm})$, then the valve 5 is opened. Under the function of gravity, the reactant material can very well drop into the container 2 .

Secondly, when a full amount of reactant in the container 1 is stored into the container 2, the valve 5 must be shut off. Subsequently, the pumping vacuum performs up to 10-15 Pa. After about $2 \mathrm{~h}$, the reactant material inside the container 2 can be preheated to about $500-600^{\circ} \mathrm{C}$ by thermal cycle from the reduction furnace 3 or the container 4 . 

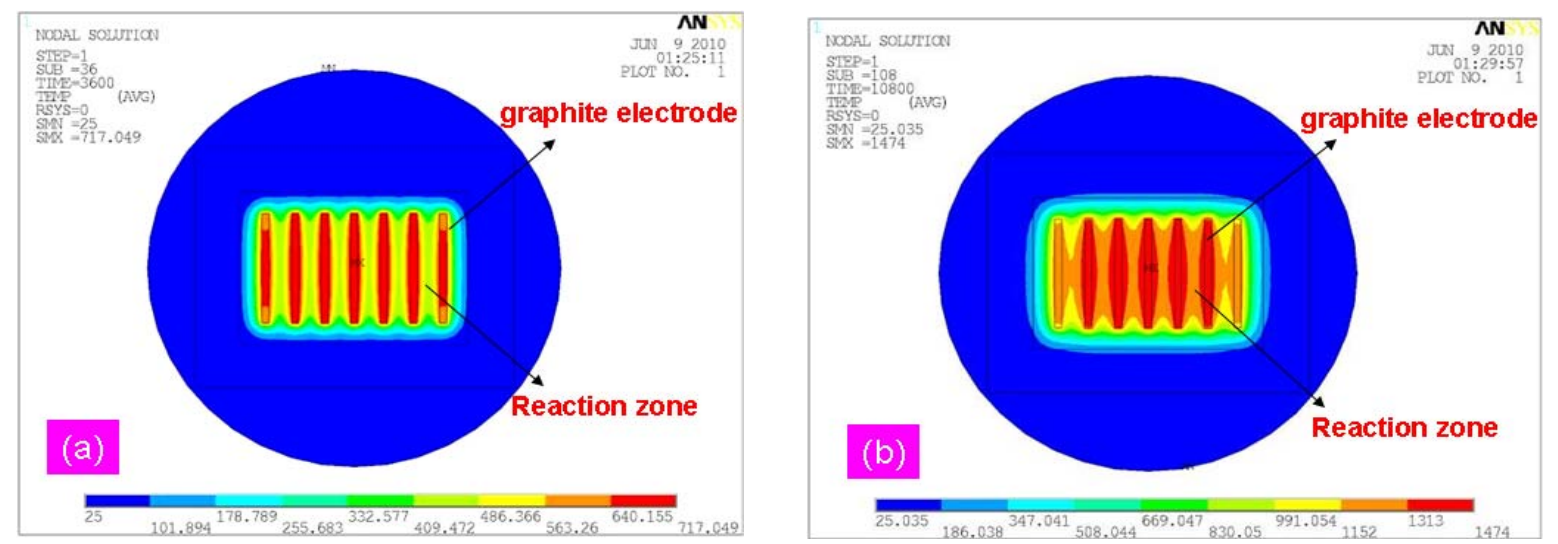

Figure 2. Temperature simulation results of the spaces between graphite electrode under unloading (a) and loading reactant material (b).

Thirdly, the valve 6 is opened, by means of gravity, the reactant material preheated can fall into the vertical furnace 3 which is about $600^{\circ} \mathrm{C}$ and a vacuum of $10-15 \mathrm{~Pa}$. When the contain 2 is empty, the valve 6 is shut down.

Fourthly, the vertical furnace can be heated as far as possible the full power. No more than $3 \mathrm{~h}$, the temperature of the vertical furnace is raised to $1200^{\circ} \mathrm{C}$ and maintained. During this stage, the reduction reaction can take place. Due to the larger gaps between heat-sources arranged regularly, the $\mathrm{Mg}$ atoms can easily overflow through the several gaps and reach condensers, which are located on both sides of the vertical furnace. Only effectively controlling the temperature gradients of the two condensers, the magnesium vapor will be crystallized into crown $\mathrm{Mg}$ inside them. One condenser is full of crown $\mathrm{Mg}$, the other one can be alternated through operating two valves between the furnace-body 3 and condenser. Figure. 3 gives the crown $\mathrm{Mg}$ taken from the condensers in semi-industrialization scale, its weight is about $90 \mathrm{Kg}$ ).

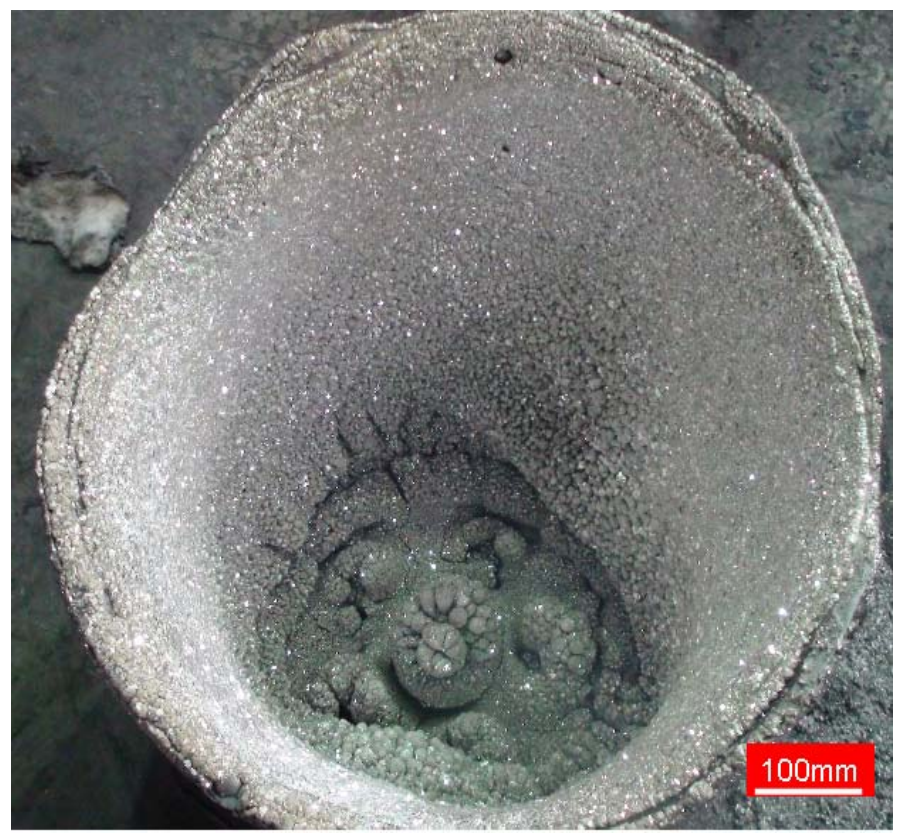

Figure.3. Crown $\mathrm{Mg}$ taken from the semi-industrialization scale.

Fifthly, after $2 \mathrm{~h}$, the reduced reaction can be performed completely. Opening the valve 8 , the red-hot residue can be eliminated from the vertical furnace 3 with help of the gravity, and stored in the container 4, which is still at the vacuum of 10-15 Pa. Due to the residue has a large amount of heat energy, in order to save and utilize the part of energy, many heat-exchanger tubes are designed in the container 4. By means of the heat exchange, the temperature of the residue can quickly decrease to about $200{ }^{\circ} \mathrm{C}$ or so. 
Finally, the valve 8 is closed and the valve 9 is opened, the cooled residue can easily remove from the container. Only the red-hot residue is discharged from the vertical furnace 3 , the new reaction materials preheated from the container 2 will be filled immediately. Like this, the continuous production comes true.

In short, with the help of the gravity and effectively control of the valves, the vertical furnace achieves continuous reduction and batch-type extracting crown $\mathrm{Mg}$.

\section{Obvious Advantageous of Vertical Reduction}

There are several significations advantageous over traditional Pigeon Process.

(1) The utilization of electrical energy inner-heating, rather than direct coal or gas outer-heating, greatly improves the rate of mass and heat transfer, accelerates the reaction rate, shorts the reduction period, reduces the industrial pollution.

(2) Because the novel reduction furnace is mainly made of the carbon steel plate and refractory materials such as firebricks and rock wool, the lifetime of the new furnace can increase to 1 year at least.

(3) Continuously process substitutes for the batch production in horizontal Pidgeon process and easily reaches the automatic control, deduces the labor intensity, and raises working efficiency.

(4) There is no limitation of the sizes of the steel retorts, the feed-stock amount of reactant material per furnace increases largely and single furnace yield improves greatly $[2,5]$.

(5) Due to the better utilization of heat energy by preheated and heat-exchanged, the energy consumption can greatly decrease to $70 \%$ of that of the horizontal Pidgeon process.

\section{References}

[1] Cherubini Francesco, Raugei Marco, Ulgiati Sergio. Resources Conservation and Recycling.52 (2008) 1093-100.

[2] Ramakrishnan S, Koltun P. Resources Conservation and Recycling. 42 (2004) 49-64.

[3] Feng Gao, Zuoren Nie and ZhihongWang.Transactions of Nonferrous Metals Society of China.18 (2008) 749-54.

[4] Alfred Yu, Henry Hu and Naiyi Li. Modelling Simul. Mater. Sci. Eng. 10 (2002) 413-423.

[5] Jindan Du, Weijian Han and Yinghong Peng. Cleaner Production.18 (2010)112-119. 